\title{
The influence of energy standardisation on the alternate Mediterranean diet score and its association with mortality in the Multiethnic Cohort
}

\author{
Yurii B. Shvetsov ${ }^{1 *}$, Brook E. Harmon ${ }^{2}$, Reynolette Ettienne ${ }^{3}$, Lynne R. Wilkens ${ }^{1}$, Loic Le Marchand ${ }^{1}$, \\ Laurence N. Kolonel ${ }^{1}$ and Carol J. Boushey ${ }^{1}$ \\ ${ }^{1}$ Cancer Center, University of Hawaii at Manoa, Honolulu, HI 96813, USA \\ ${ }^{2}$ Division of Social and Behavioral Sciences, School of Public Health, University of Memphis, Memphis, TN 38152, USA \\ ${ }^{3}$ Department of Human Nutrition, Food and Animal Sciences, University of Hawaii at Manoa, Honolulu, HI 96822, USA
}

(Submitted 23 October 2015 - Final revision received 17 August 2016 - Accepted 9 September 2016 - First published online 21 October 2016)

\section{Abstract}

The alternate Mediterranean diet (aMED) score is an adaptation of the original Mediterranean diet score. Raw (aMED) and energy-standardised (aMED-e) versions have been used. How the diet scores and their association with health outcomes differ between the two versions is unclear. We examined differences in participants' total and component scores and compared the association of aMED and aMED-e with all-cause, CVD and cancer mortality. As part of the Multiethnic Cohort, 193527 men and women aged 45-75 years from Hawaii and Los Angeles completed a baseline FFQ and were followed up for 13-18 years. The association of aMED and aMED-e with mortality was examined using Cox's regression, with adjustment for total energy intake. The correlation between aMED and aMED-e total scores was lower among people with higher BMI. Participants who were older, leaner, more educated and consumed less energy scored higher on aMED-e components compared with aMED, except for the red and processed meat and alcohol components. Men reporting more physical activity scored lower on most aMED-e components compared with aMED, whereas the opposite was observed for the meat component. Higher scores of both aMED and aMED-e were associated with lower risk of all-cause, CVD and cancer mortality. Although individuals may score differently with aMED and aMED-e, both scores show similar reductions in mortality risk for persons scoring high on the index scale. Either version can be used in studies of diet and mortality. Comparisons can be performed across studies using different versions of the score.

\section{Key words: Mediterranean diet: Diet scores: Energy intake: Mortality}

The traditional Mediterranean dietary pattern is characterised by a generous intake of vegetables, legumes, fruits, nuts, cereals and fish, as well as a high ratio of MUFA:SFA ${ }^{(1)}$. Other characteristics include moderate intakes of alcohol and dairy products mostly as yogurt and cheese, and low intakes of red or processed meats and sweets. The use of dietary scores stems from the idea that the overall dietary pattern may be more important for health and longevity than the individual nutritional or food components. The Mediterranean dietary score (MDS) was first introduced in 1995 on the basis of eight food/ beverage components ${ }^{(1)}$ and subsequently refined ${ }^{(2)}$ in Greece. Investigators in Europe have extensively studied this and other variations of the Mediterranean diet score, which differed in the overall scale (ref: Trichopolou 2, Estruch, Papagiotakos) and in their measurement of individual dietary components such as assessment of olive oil intake as a separate item or, alternatively, the use of MUFA:SFA (ref: Estruch, Trichopolou 2). Researchers in the USA have subsequently modified the traditional MDS to reflect eating patterns in the USA ${ }^{(3)}$. This alternate Mediterranean diet score (aMED), with scores ranging from 0 to 9, was created to accommodate researchers studying the association of diet with the risk of chronic disease in North American populations.

Both MDS and aMED have been consistently linked with a reduction in the incidence of CVD, stroke, cancer, diabetes and with a reduced risk of all-cause, CVD and cancer mortality $^{(4-19)}$. Adjustment for estimated energy intake is usually performed in epidemiological studies to control confounding and reduce extraneous variation, and it can be achieved in a number of ways ${ }^{(20)}$. The MDS standardises the sex-specific energy intake levels and adjusts for total energy intake. However, energy standardisation has been inconsistent for the aMED. Some studies ${ }^{(3,6-9,14-19)}$ used raw component intakes to compute the total score and subsequently adjusted the models for energy intake, and others ${ }^{(10-12)}$ used energy adjustment and energy-standardised component intakes in the computation

Abbreviations: aMED, alternate Mediterranean diet score; aMED-e, energy-standardised alternate Mediterranean diet score; MDS, Mediterranean dietary score; MEC, Multiethnic Cohort; QFFQ, quantitative FFQ

* Corresponding author: Y. B. Shvetsov, fax +1 808586 2982, email yshvetso@cc.hawaii.edu 
of the total score (aMED-e). It is unclear how the diet scores and their association with health outcomes differ between the two versions and whether studies using different aMED versions can be meaningfully compared.

The Dietary Patterns Methods Project (DPMP), established by the National Cancer Institute, was designed to strengthen scientific evidence relating diet to mortality through simultaneous identical analyses in three established US cohorts ${ }^{(15-18)}$ of the association between four dietary indices and all-cause, CVD and cancer mortality. This seminal family of studies used aMED as one of the dietary indices. To date, an examination of aMED and aMED-e with regard to individuals being assigned the same score and whether the overall results yield similar risk estimates has not been performed. Such an analysis would provide guidance for comparison across studies using different aMED versions.

The Multiethnic Cohort (MEC) was part of the DPMP ${ }^{(17)}$. In the present report, we use a larger sample of older men and women participating in the MEC to study the effect of energy standardisation on the Mediterranean diet score and how this effect varies among score components and different groups of cohort participants. We also prospectively examine and compare the association of aMED and aMED-e scores with mortality.

\section{Methods \\ Study population and case ascertainment}

The MEC is a prospective cohort study of adults from five racial/ ethnic groups in Hawaii and Los Angeles, established to examine the association of lifestyle and genetic factors with the risk of cancer and other chronic diseases ${ }^{(21)}$. Over 215000 men and women aged 45-75 years were recruited between 1993 and 1996. At cohort entry, participants completed a mail-in selfadministered detailed baseline questionnaire (Qx1), which was treated as an informed consent and included information on demographics, anthropometric measures, medical history, reproductive history (women), occupational history, food intake and physical activity. Participants missing demographic and other essential information were excluded. The MEC study protocol was approved by the Institutional Review Boards of the University of Hawaii and the University of Southern California.

Deaths from causes other than cancer were identified using state death files and the National Death Index. Deaths from CVD were identified and classified as International Classification of Diseases, Ninth Revision (ICD-9) codes 390-448 or ICD-10 codes $\mathrm{I} 00-\mathrm{I} 78$ and $\mathrm{G} 45^{(22,23)}$. Cancer deaths were identified through linkages to the Hawaii Tumor Registry, the Cancer Surveillance Program for Los Angeles County and the California State Cancer Registry, which are part of the US National Cancer Institute's Surveillance, Epidemiology, and End Results Program, and the US National Death Index. Cancer deaths were classified using ICD-9 codes 140-208 or ICD-10 codes $\mathrm{C} 00-\mathrm{C} 97^{(22,23)}$. All-cause mortality included $\mathrm{CVD}$ and cancer deaths, as well as deaths from other causes, including accidents and suicides. All death files were current up to 31 December 2011 for participants in Hawaii and 31 October 2010 for Los Angeles participants. Participants with no recorded death as of these dates were censored.

\section{Dietary assessment and score calculation}

The Qx1 included a 182-item quantitative FFQ (QFFQ), which has been described in detail elsewhere ${ }^{(21,24,25)}$. Usual intake over the past 12 months was assessed using eight categories, from 'never or hardly ever' to 'two or more times a day', and nine categories, from 'never or hardly ever' to 'four or more times a day', for some beverage items. Quantities of foods were assessed using three portion sizes specific to each food item, which were shown as representative images. The QFFQ was validated and calibrated in each ethnic-sex group using data from 1606 participants and three randomly scheduled 24-h dietary recalls $^{(24)}$. The MEC QFFQ has several unique attributes, including the presence of ethnic-specific foods, reliance on a food composition table specific to the MEC and use of a large recipe database ${ }^{(26)}$.

The foods and beverages in the QFFQ were disaggregated using the MEC food composition tables ${ }^{(25)}$, to create the major food groups and subgroups that make up the MyPyramid Equivalents Database (MPED), a standardised food-grouping system developed by the US Department of Agriculture that disaggregates most foods into their ingredients and allocates each ingredient to one of thirty-two food groups ${ }^{(27)}$. Amounts of foods reported were converted from 'portions' to 'cup equivalents' or 'ounce equivalents'. The MPED groups and subgroups were used to construct each component contributing to aMED and aMED-e. The component scores of aMED were based on total component intake, whereas those of aMED-e were based on intake standardised to $8368 \mathrm{~kJ}(2000 \mathrm{kcal})$ in women and $10460 \mathrm{~kJ}(2500 \mathrm{kcal})$ in men ${ }^{(10-12)}$. One point was assigned for intake above the sex-specific median for the healthful components or below the sex-specific median for the fat ratio component:red meat component. Specific intakes for men $(10-25 \mathrm{~g} / \mathrm{d})$ and women $(5-15 \mathrm{~g} / \mathrm{d})$ were used for the alcohol component. The total score was calculated as the sum of all component scores and ranged between 0 and 9. The components of aMED and aMED-e, their composition and scoring criteria for MEC participants are listed in Table 1.

\section{Statistical analysis}

Analyses were limited to cohort participants from five main MEC ethnic groups (white, African-American, JapaneseAmerican, Native Hawaiian, Latino) who had valid dietary assessment information. To better represent the general population, individuals with prior history of cancer or heart disease at baseline were not excluded. A total of 87338 men and 106189 women were included in the analyses.

Diet scores were divided into quintiles using separate cut-off points for men and women. BMI was categorised as normal weight $\left(<25 \mathrm{~kg} / \mathrm{m}^{2}\right)$, overweight $\left(25-29.9 \mathrm{~kg} / \mathrm{m}^{2}\right)$ and obese $\left(\geq 30 \mathrm{~kg} / \mathrm{m}^{2}\right.$ ) using self-reported height and weight. The effect of energy standardisation on the diet score was assessed by examining the distributions of aMED and aMED-e scores by sex, age group, ethnicity and BMI. We calculated the percentage of 
Table 1. Components, optimal quantities and scoring standards for the alternate Mediterranean diet score (aMED) variations among the Multiethnic Cohort participants

\begin{tabular}{|c|c|c|c|c|c|c|}
\hline \multirow[b]{3}{*}{ Components } & \multirow[b]{3}{*}{ Foods included } & \multirow[b]{3}{*}{ Scoring criterion* } & \multicolumn{4}{|c|}{ Scoring cut-off points $\dagger$} \\
\hline & & & \multicolumn{2}{|c|}{ Men } & \multicolumn{2}{|c|}{ Women } \\
\hline & & & aMED & aMED-e & aMED & aMED-e \\
\hline Fruits & All fruits and $100 \%$ fruit juices & Servings $/ d>$ median intake & 1.57 & 1.80 & 1.84 & 2.07 \\
\hline Vegetables & All vegetables except potatoes & Servings/d > median intake & 1.66 & 1.86 & 1.71 & 1.89 \\
\hline Legumes & Dried beans and peas, lentils, tofu, soya & Servings/d > median intake & 0.09 & 0.10 & 0.07 & 0.08 \\
\hline Nuts & Nuts and peanut butter & Servings/d > median intake & 0.44 & 0.50 & 0.34 & 0.38 \\
\hline Whole grains & $\begin{array}{l}\text { Whole-grain ready-to-eat cereals, cooked cereals, } \\
\text { crackers, dark breads, brown rice, other whole grains }\end{array}$ & Servings/d > median intake & $1 \cdot 23$ & 1.40 & $1 \cdot 30$ & 1.45 \\
\hline Fish & Fish, shellfish, canned fish, dried fish & Servings $/ d>$ median intake & 0.64 & 0.74 & 0.48 & 0.55 \\
\hline Red and processed meats & Red meats, processed meats & Servings $/ \mathrm{d}<$ median intake & 1.98 & $2 \cdot 30$ & 1.32 & 1.52 \\
\hline MUFA:SFA ratio & MUFA (g):SFA (g) & Ratio > median & \multicolumn{2}{|c|}{1.22} & \multicolumn{2}{|c|}{1.20} \\
\hline Alcohol & Beer, hard liquor, wine & Intake within specified range (g/d) & $10-25$ & $10-25$ & $5-15$ & 5-15 \\
\hline
\end{tabular}

aMED-e, energy-standardised alternate Mediterranean diet; MEC, Multiethnic Cohort.

* Component score $=1$, if the criterion is met; 0 , otherwise.

$\dagger$ Median (servings/d) for all components except alcohol and MUFA:SFA ratio. Specified range (g/d) for alcohol. Medians for all components were established separately for men and women in the MEC.

Table 2. Distribution (\%) of alternate Mediterranean diet (aMED) and energy-standardised alternate Mediterranean diet (aMED-e) scores by sex in the Multiethnic Cohort

\begin{tabular}{|c|c|c|c|c|c|c|c|c|}
\hline \multirow[b]{3}{*}{ Scores } & \multicolumn{4}{|c|}{ Men ( $n$ 87 338) } & \multicolumn{4}{|c|}{ Women (n 106 189) } \\
\hline & \multicolumn{2}{|c|}{ aMED (\%) } & \multicolumn{2}{|c|}{ aMED-e (\%) } & \multicolumn{2}{|c|}{ aMED (\%) } & \multicolumn{2}{|c|}{ aMED-e (\%) } \\
\hline & & Cumulative & & Cumulative & & Cumulative & & Cumulative \\
\hline 0 & 0.8 & 0.8 & 0.8 & 0.8 & 0.8 & 0.8 & 0.7 & 0.7 \\
\hline 1 & 5.9 & $6 \cdot 6$ & $5 \cdot 0$ & $5 \cdot 8$ & $6 \cdot 4$ & $7 \cdot 3$ & $5 \cdot 0$ & 5.7 \\
\hline 2 & 13.2 & $19 \cdot 8$ & 12.4 & 18.2 & 13.9 & 21.2 & $12 \cdot 6$ & $18 \cdot 3$ \\
\hline 3 & 17.8 & 37.6 & $18 \cdot 7$ & 36.9 & $18 \cdot 1$ & $39 \cdot 3$ & 19.4 & 37.7 \\
\hline 4 & $19 \cdot 6$ & $57 \cdot 2$ & 21.5 & $58 \cdot 3$ & $19 \cdot 1$ & $58 \cdot 4$ & $22 \cdot 2$ & 59.8 \\
\hline 5 & 18.0 & $75 \cdot 2$ & 19.1 & 77.4 & 18.0 & $76 \cdot 4$ & $19 \cdot 6$ & 79.4 \\
\hline 6 & 14.7 & 89.9 & 13.4 & $90 \cdot 8$ & 14.4 & $90 \cdot 8$ & $12 \cdot 9$ & 92.4 \\
\hline 7 & 7.9 & $97 \cdot 7$ & 6.9 & $97 \cdot 7$ & 7.4 & 98.2 & 6.0 & 98.4 \\
\hline 8 & $2 \cdot 1$ & 99.8 & $2 \cdot 0$ & 99.8 & 1.7 & 99.9 & 1.5 & 99.9 \\
\hline 9 & 0.2 & $100 \cdot 0$ & 0.2 & $100 \cdot 0$ & 0.1 & 100.0 & 0.1 & $100 \cdot 0$ \\
\hline
\end{tabular}

participants whose aMED-e score changed or remained the same, compared with the aMED score. We also examined individual scores for the dietary components comprising the Mediterranean diet, and computed percentage of participants scoring 1 point according to the component score guidelines before and after energy standardisation, as well as the percentage of those whose component scores changed. To characterise participants who were more likely to experience component score change, we calculated mean age at cohort entry, education level, BMI, physical activity level and total energy intake by component score and total score change level (decrease, unchanged, increase). Linear regression was used to estimate the linear trend in component score change by each of these factors.

The associations of aMED and aMED-e diet scores with allcause, CVD and cancer mortality were examined using Cox's regression with years since study entry as the time metric. For CVD and cancer models, study participants who died of other causes were considered censored at the time of death. Hazard ratios and $95 \%$ CI were calculated for diet score quintiles, represented by four indicator variables. The lowest quintile was used as a reference category. Linear trend was evaluated based on the median dietary score within each quintile. Analyses were adjusted for age at baseline (continuous), ethnicity (as indicator variables), BMI (normal weight, overweight, obese), moderateto-vigourous physical activity $(<2.5, \geq 2.5 \mathrm{~h} /$ week $)$, smoking (current smoker, past smoker, never smoked), education $(<12$, $12,13-15,16$ or more years) as a proxy of socio-economic status, marital status (married, not married), hormone replacement therapy (yes, no - women only) and history of diabetes, heart disease and cancer (yes, no). Continuous measures (age at baseline and total energy intake) had no missing values because of our inclusion criteria. Categorical covariates with missing values were modelled with a separate missing value category. Missing values ranged from $<1$ to $2 \cdot 3 \%$ of the total sample. Models were fit with and without additional adjustment for the total energy intake (continuous) and were stratified by sex and ethnicity. Analyses were repeated with participants' age as time metric and with follow-up restricted to 5 and 10 years. The proportional hazard assumption for Cox's models was 
verified by plotting scaled Schoenfeld residuals against time to event $^{(28)}$. All analyses were conducted with SAS version 9.3 (SAS Institute Inc.). All $P$ values were two-sided and $P<0.05$ was defined as significant.

\section{Results}

At the end of 13-18 years of follow-up, a total of 51702 deaths (27744 among men, 23958 among women) were recorded, of which 19000 (10 433 men, 8567 women) were from CVD and 16414 (8811 men, 7603 women) from cancer.

The majority of cohort participants scored between 2 and 6 on both aMED and aMED-e (Table 2). Total scores of 1 and 7 were less common ( $<7$ and $<8 \%$ participants, respectively), scores of $0(<1 \%)$ and 8 (about $2 \%)$ were rare and a score of 9 $(<0.3 \%)$ was very rare. On average, energy intake standardisation had the effect of shifting total scores towards the middle values of 3-5 among both men and women.

To assess how the effect of energy standardisation changes by age and ethnicity, we compared the correlation between the aMED and aMED-e total scores and the percentage of participants who scored the same on both scores (Table 3). There was little difference by age group in the correlation between the aMED and aMED-e. Men were slightly more likely than women to score the same on aMED and aMED-e. The percentage of participants whose aMED-e score was higher than aMED steadily increased with age, with approximately $31 \%$ of older men and women scoring higher on aMED-e. White and Japanese American participants had higher correlations between the two scores. Native Hawaiians had the lowest percentage and African-Americans the highest percentage of those who had higher aMED-e scores. These two ethnic groups also had the lowest fraction of those who had identical aMED and aMED-e scores. The correlation between the total scores, as well as the percentage of those scoring higher on aMED-e, was lower among participants with higher BMI.

We also examined individual scores of the nine components of the Mediterranean diet among the MEC men and women (Table 4). One component, MUFA:SFA ratio, was unaffected by energy standardisation. In seven components, nearly half of the cohort participants scored ' 1 '. A notable exception was alcohol, with $<15 \%$ men and $<8 \%$ women scoring ' 1 ' on either aMED or aMED-e. Although the percentage of participants scoring ' 1 ' was similar between aMED and aMED-e for all components, there was substantial difference in the individual scores, as evidenced in the percent discordant scores - that is, ' 1 ' for one version of the diet score and ' 0 ' for the other. The highest fraction of discordant component scores was observed for vegetables ( $24 \%$ men and women), followed by red and processed meat (20\% men and $19 \%$ women).

The groups of cohort participants whose component scores changed after energy standardisation are characterised in Table 5. We computed mean age at baseline, education, BMI, physical activity and total energy intake separately among three groups of participants: those whose component scores decreased, increased or remained the same. For all components, except alcohol and red and processed meat, men and women whose component scores increased after energy

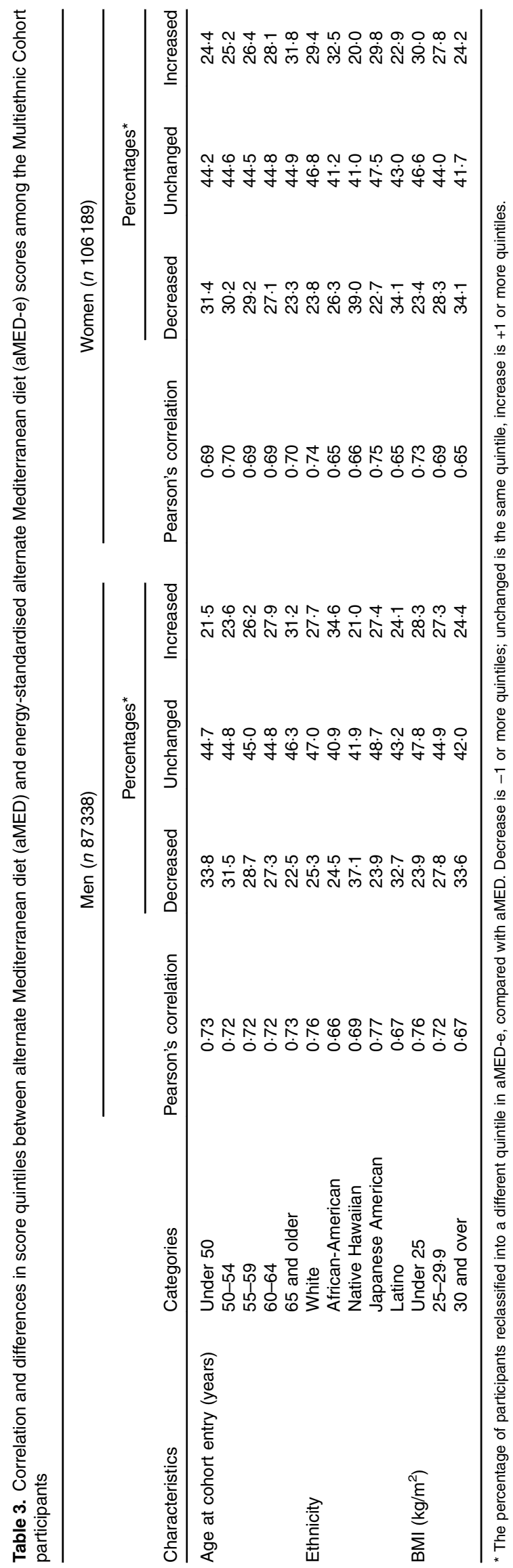


Table 4. Percent scoring 1 by alternate Mediterranean diet (aMED) and energy-standardised alternate Mediterranean diet (aMED-e) food components by sex in the Multiethnic Cohort

\begin{tabular}{|c|c|c|c|c|c|c|}
\hline \multirow[b]{3}{*}{ Components } & \multicolumn{3}{|c|}{ Men ( $n$ 87 338) } & \multicolumn{3}{|c|}{ Women (n 106 189) } \\
\hline & \multicolumn{2}{|c|}{ Percent scoring ' 1 ' } & \multirow[b]{2}{*}{ Percent discordant ${ }^{\star}$} & \multicolumn{2}{|c|}{ Percent scoring ' 1 ' } & \multirow[b]{2}{*}{ Percent discordant $^{\star}$} \\
\hline & aMED & aMED-e & & aMED & aMED-e & \\
\hline Vegetables & 49.9 & $49 \cdot 9$ & $23 \cdot 7$ & $49 \cdot 8$ & $50 \cdot 1$ & $24 \cdot 0$ \\
\hline Fruit & $50 \cdot 0$ & $49 \cdot 7$ & $15 \cdot 8$ & $49 \cdot 8$ & $49 \cdot 7$ & $17 \cdot 2$ \\
\hline Nuts & $50 \cdot 3$ & $50 \cdot 2$ & $13 \cdot 8$ & 49.8 & 49.8 & $13 \cdot 4$ \\
\hline Legumes & $50 \cdot 9$ & $50 \cdot 8$ & $12 \cdot 0$ & $50 \cdot 9$ & $51 \cdot 0$ & $11 \cdot 7$ \\
\hline Fish & $49 \cdot 3$ & $49 \cdot 2$ & $15 \cdot 5$ & $49 \cdot 2$ & $49 \cdot 2$ & 15.4 \\
\hline Grains & $51 \cdot 3$ & $51 \cdot 1$ & $13 \cdot 2$ & $51 \cdot 0$ & 51.0 & $15 \cdot 0$ \\
\hline Alcohol & 14.4 & $14 \cdot 6$ & $10 \cdot 0$ & $7 \cdot 7$ & 8.0 & 5.4 \\
\hline Red and processed meat & $49 \cdot 9$ & $49 \cdot 7$ & $20 \cdot 5$ & $50 \cdot 2$ & 49.9 & $19 \cdot 0$ \\
\hline MUFA:SFA ratio & $49 \cdot 8$ & 49.8 & 0.0 & 49.6 & $49 \cdot 6$ & 0.0 \\
\hline
\end{tabular}

* Percentage of the participants whose component score changed (from 0 to 1 or from 1 to 0 ) in aMED-e, compared with aMED.

standardisation tended to be older, leaner and more educated and to have lower energy intake. Men whose component scores decreased were more physically active, whereas women with decreased component scores were slightly less or equally active than whose component scores improved or did not change. The opposite trends were observed for red and processed meat component scores. Little difference among the three participant groups was found for alcohol scores.

Both versions of the Mediterranean diet score showed inverse associations with all-cause, CVD and cancer mortality among men and women in all ethnicity analyses (Table 6; online Supplementary Table S1). Estimates for aMED-e with and without additional adjustment for energy intake were identical (data not shown). Compared with aMED with energy adjustment in the model, aMED-e exhibited the same or slightly stronger associations with all-cause and CVD mortality and slightly weaker associations with cancer mortality for most sex-ethnic groups. The majority of statistically significant associations were observed among White and African-American participants. Although the estimates for Native Hawaiians are mostly not statistically significant, they are still very similar between aMED and aMED-e. Without energy adjustment in the model, the estimates for highest $v$. lowest quintile of aMED were also in the negative direction, but of smaller magnitude (attenuated towards 1) than those from energy-adjusted models, and for African-American women it resulted in the loss of statistical significance. Analyses with participants' age as time metric and with follow-up restricted to 5 and 10 years yielded estimates 3, 6 and $8 \%$, respectively, of those reported in Table 6 (data not shown).

\section{Discussion}

The aMED and aMED-e appear to be distinctly different diet scores, which are more closely correlated among those of older age, lower BMI and higher physical activity, and differ more widely among those with higher BMI and higher total energy intake. We have observed that although the overall distribution of the two scores appears very close the individual aMED and aMED-e scores may differ substantially within individuals.
This suggests that a choice between raw and energystandardised Mediterranean diet score deserves some attention.

We observed that among individuals whose total aMED-e score decreased, compared with aMED, average energy intakes were higher. This is not surprising. The unstandardised aMED score measures total consumption of food components and the aMED-e score reflects the proportion of these components within a standardised amount of energy. Therefore, higherenergy-intake individuals may score well on the total consumption of component foods but lag behind in the proportion of these foods, if they are consuming even greater amounts of other, less beneficial foods. This observation underscores that consuming high amounts of healthy foods does not in itself constitute a healthy diet.

Diet scores increased after energy standardisation among older participants, which may reflect their healthier overall eating habits or reduced total food intake. Energy standardisation also tended to reduce the diet score among physically active men. It is conceivable that physically active individuals would eat more to satisfy their increased energy needs ${ }^{(29)}$, and thus the above observation on high-energy-intake individuals may explain this finding. We note, however, that this finding was not observed in women. The correlation of physical activity and total food intake was also weaker in women compared with men in our study (data not shown). Potential reasons for this may include under-reporting of food intake by physically active women, or a possibility that women undertaking weightloss effort may increase their physical activity but not their food intake ${ }^{(29,30)}$.

The problem of estimating energy intake from self-reported dietary data has received much attention ${ }^{(31,32)}$. Most FFQ are not considered appropriate dietary assessment tools to estimate true energy intake ${ }^{(33)}$. Energy intakes derived from FFQ have been found to be underestimated primarily because of the specific set of foods and beverages included in the FFQ that may not cover an individual's entire diet ${ }^{(34)}$. At the same time, it has been observed that because the error in self-reported energy correlates with that in the reported intake of foods and beverages adjustment for the self-reported energy intake can actually correct for measurement error in other dietary 
Table 5. Characteristics of participants by alternate Mediterranean diet (aMED) to energy-standardised alternate Mediterranean diet (aMED-e) component score change, by food component and sex in the Multiethnic Cohort

\begin{tabular}{|c|c|c|c|c|c|c|c|c|c|c|c|c|c|}
\hline \multirow[b]{2}{*}{ Components } & \multirow[b]{2}{*}{$\begin{array}{l}\text { Score } \\
\text { change* }\end{array}$} & \multicolumn{6}{|c|}{ Men ( $n$ 87338) } & \multicolumn{6}{|c|}{ Women (n 106 189) } \\
\hline & & $n$ & $\begin{array}{l}\text { Age at cohort } \\
\text { entry (mean) }\end{array}$ & $\begin{array}{c}\text { Years of } \\
\text { school (mean) }\end{array}$ & $\begin{array}{c}\text { BMI } \\
\text { (mean) }\end{array}$ & $\begin{array}{l}\text { MET of } \\
\text { activity/d } \\
\text { (mean)† }\end{array}$ & $\begin{array}{l}\text { Total energy } \\
\text { intake (mean) }\end{array}$ & $n$ & $\begin{array}{l}\text { Age at cohort } \\
\text { entry (mean) }\end{array}$ & $\begin{array}{c}\text { Years of } \\
\text { school (mean) }\end{array}$ & $\begin{array}{c}\text { BMI } \\
\text { (mean) }\end{array}$ & $\begin{array}{l}\text { MET of } \\
\text { activity/d } \\
\text { (mean)† }\end{array}$ & $\begin{array}{l}\text { Total energy } \\
\text { intake (mean) }\end{array}$ \\
\hline \multirow[t]{4}{*}{ Vegetables } & 1 to 0 & 10348 & $58 \cdot 8$ & $12 \cdot 6$ & 27.5 & 1.69 & 3861 & 12605 & $58 \cdot 8$ & $12 \cdot 4$ & $27 \cdot 8$ & 1.58 & 3237 \\
\hline & Unchanged & 66612 & 60.8 & $13 \cdot 3$ & $26 \cdot 6$ & 1.66 & 2366 & 80753 & 60.3 & 13.1 & 26.4 & 1.59 & 1925 \\
\hline & 0 to 1 & 10378 & $62 \cdot 3$ & 13.4 & $26 \cdot 5$ & 1.65 & 1385 & 12831 & $61 \cdot 4$ & $13 \cdot 2$ & $25 \cdot 8$ & 1.60 & 1117 \\
\hline & $P$ value $\ddagger$ & & $<0.001$ & 0.004 & 0.30 & $<0.001$ & $<0.001$ & & $<0.001$ & $<0.001$ & 0.01 & $<0.001$ & $<0.001$ \\
\hline \multirow[t]{4}{*}{ Fruit } & 1 to 0 & 7009 & $59 \cdot 3$ & $12 \cdot 8$ & 27.5 & 1.69 & 3928 & 9181 & 59.1 & $12 \cdot 6$ & 27.9 & 1.59 & 3281 \\
\hline & Unchanged & 73529 & 60.7 & $13 \cdot 3$ & $26 \cdot 6$ & 1.66 & 2385 & 87927 & $60 \cdot 2$ & 13.0 & $26 \cdot 4$ & 1.59 & 1940 \\
\hline & 0 to 1 & 6800 & $62 \cdot 9$ & $13 \cdot 3$ & $26 \cdot 4$ & 1.65 & 1326 & 9081 & $62 \cdot 2$ & $13 \cdot 2$ & 26.0 & 1.61 & 1083 \\
\hline & $P$ value $\ddagger$ & & $<0.001$ & $<0.001$ & 0.81 & 0.15 & $<0.001$ & & $<0.001$ & 0.92 & 0.93 & $<0.001$ & $<0.001$ \\
\hline \multirow[t]{4}{*}{ Nuts } & 1 to 0 & 6085 & 58.6 & $12 \cdot 6$ & 27.5 & 1.70 & 3898 & 7113 & 58.7 & $12 \cdot 4$ & 28.0 & 1.59 & 3236 \\
\hline & Unchanged & 75303 & $60 \cdot 8$ & $13 \cdot 2$ & $26 \cdot 6$ & 1.66 & 2392 & 91955 & $60 \cdot 3$ & 13.0 & $26 \cdot 5$ & 1.59 & 1955 \\
\hline & 0 to 1 & 5950 & $62 \cdot 1$ & $13 \cdot 6$ & 26.5 & 1.65 & 1355 & 7121 & 61.0 & 13.4 & 26.0 & 1.59 & 1100 \\
\hline & $P$ value $\ddagger$ & & $<0.001$ & 0.003 & 0.83 & 0.42 & $<0.001$ & & $<0.001$ & $<0.001$ & 0.03 & 0.91 & $<0.001$ \\
\hline \multirow[t]{4}{*}{ Legumes } & 1 to 0 & 5286 & $58 \cdot 7$ & $13 \cdot 6$ & $27 \cdot 2$ & 1.68 & 3723 & 6130 & 59.0 & $13 \cdot 3$ & $27 \cdot 4$ & 1.57 & 3151 \\
\hline & Unchanged & 76887 & $60 \cdot 8$ & $13 \cdot 2$ & $26 \cdot 6$ & 1.67 & 2413 & 93747 & $60 \cdot 3$ & $13 \cdot 0$ & $26 \cdot 5$ & 1.59 & 1969 \\
\hline & 0 to 1 & 5165 & $62 \cdot 1$ & 13.5 & $26 \cdot 5$ & 1.64 & 1296 & 6312 & 61.3 & 13.1 & $26 \cdot 4$ & 1.60 & 1058 \\
\hline & $P$ value $\ddagger$ & & 0.004 & $<0.001$ & $<0.001$ & 0.32 & $<0.001$ & & 0.61 & $<0.001$ & $<0.001$ & $<0.001$ & $<0.001$ \\
\hline \multirow[t]{4}{*}{ Fish } & 1 to 0 & 6781 & $59 \cdot 3$ & $12 \cdot 7$ & $27 \cdot 3$ & 1.69 & 3869 & 8142 & $59 \cdot 1$ & $12 \cdot 6$ & $27 \cdot 6$ & 1.59 & 3213 \\
\hline & Unchanged & 73815 & $60 \cdot 8$ & $13 \cdot 2$ & $26 \cdot 6$ & 1.66 & 2394 & 89877 & $60 \cdot 3$ & $13 \cdot 0$ & 26.5 & 1.59 & 1954 \\
\hline & 0 to 1 & 6742 & $62 \cdot 1$ & 13.5 & $26 \cdot 4$ & 1.64 & 1324 & 8170 & $61 \cdot 1$ & $13 \cdot 2$ & 26.0 & 1.59 & 1074 \\
\hline & $P$ value $\ddagger$ & & 0.12 & 0.37 & 0.04 & 0.98 & $<0.001$ & & 0.53 & 0.12 & 0.13 & 0.28 & $<0.001$ \\
\hline \multirow[t]{4}{*}{ Grains } & 1 to 0 & 5871 & 59.2 & $12 \cdot 7$ & 27.5 & 1.69 & 4009 & 7960 & 59.1 & $12 \cdot 4$ & 28.0 & 1.58 & 3375 \\
\hline & Unchanged & 75811 & $60 \cdot 7$ & $13 \cdot 2$ & $26 \cdot 6$ & 1.67 & 2386 & 90246 & $60 \cdot 3$ & $13 \cdot 0$ & $26 \cdot 4$ & 1.59 & 1940 \\
\hline & 0 to 1 & 5656 & 62.5 & $13 \cdot 7$ & $26 \cdot 6$ & 1.63 & 1323 & 7983 & $61 \cdot 4$ & $13 \cdot 3$ & $26 \cdot 1$ & 1.59 & 1085 \\
\hline & $P$ value $\ddagger$ & & $<0.001$ & 0.006 & 0.002 & 0.40 & $<0.001$ & & $<0.001$ & 0.001 & 0.64 & 0.006 & $<0.001$ \\
\hline \multirow[t]{4}{*}{ Alcohol } & 1 to 0 & 4242 & $60 \cdot 3$ & 13.4 & 26.5 & 1.67 & 2313 & 2718 & 58.7 & $13 \cdot 6$ & $25 \cdot 8$ & 1.60 & 2138 \\
\hline & Unchanged & 78649 & $60 \cdot 8$ & $13 \cdot 2$ & $26 \cdot 6$ & 1.66 & 2426 & 100502 & $60 \cdot 4$ & 13.0 & $26 \cdot 6$ & 1.59 & 1984 \\
\hline & 0 to 1 & 4447 & 59.7 & $13 \cdot 1$ & $27 \cdot 1$ & 1.67 & 2531 & 2969 & 58.7 & 13.7 & $25 \cdot 9$ & 1.58 & 1812 \\
\hline & $P$ value $\ddagger$ & & 0.07 & $<0.001$ & $<0.001$ & 0.57 & $<0.001$ & & 0.04 & 0.72 & 0.20 & 0.19 & $<0.001$ \\
\hline \multirow{4}{*}{$\begin{array}{l}\text { Red and } \\
\text { processed } \\
\text { meat }\end{array}$} & 1 to 0 & 9019 & 61.7 & 13.2 & $26 \cdot 8$ & 1.64 & 1336 & 10251 & 60.9 & $12 \cdot 9$ & 26.5 & 1.59 & 1073 \\
\hline & Unchanged & 69472 & $60 \cdot 7$ & $13 \cdot 3$ & $26 \cdot 6$ & 1.66 & 2403 & 85988 & $60 \cdot 2$ & $13 \cdot 0$ & 26.5 & 1.59 & 1959 \\
\hline & 0 to 1 & 8847 & 59.9 & $12 \cdot 8$ & $26 \cdot 9$ & 1.70 & 3716 & 9950 & $60 \cdot 1$ & $12 \cdot 7$ & $27 \cdot 0$ & 1.60 & 3124 \\
\hline & $P$ value $\ddagger$ & & $<0.001$ & $<0.001$ & $<0.001$ & $<0.001$ & $<0.001$ & & $<0.001$ & $<0.001$ & $<0.001$ & 0.02 & $<0.001$ \\
\hline \multirow{4}{*}{$\begin{array}{l}\text { Total score } \\
\text { change }\end{array}$} & -1 or more & 23924 & $59 \cdot 3$ & $12 \cdot 9$ & 27.2 & 1.68 & 3450 & 29017 & $59 \cdot 3$ & $12 \cdot 7$ & 27.5 & 1.59 & 2881 \\
\hline & Unchanged & 39638 & 60.9 & $13 \cdot 3$ & 26.5 & 1.66 & 2289 & 47404 & $60 \cdot 3$ & 13.1 & $26 \cdot 3$ & 1.59 & 1860 \\
\hline & +1 or more & 23776 & $62 \cdot 0$ & 13.4 & $26 \cdot 4$ & 1.65 & 1624 & 29768 & $61 \cdot 2$ & $13 \cdot 2$ & $26 \cdot 0$ & 1.60 & 1304 \\
\hline & $P$ value $\ddagger$ & & $<0.001$ & 0.78 & 0.27 & 0.14 & $<0.001$ & & $<0.001$ & 0.01 & 0.004 & $<0.001$ & $<0.001$ \\
\hline \multirow{4}{*}{$\begin{array}{l}\text { Total score } \\
\text { change } \\
\text { (quintile) }\end{array}$} & -1 or more & 20125 & $59 \cdot 2$ & $12 \cdot 8$ & 27.4 & 1.68 & 3528 & 24672 & $59 \cdot 1$ & $12 \cdot 6$ & $27 \cdot 7$ & 1.58 & 2948 \\
\hline & Unchanged & 47108 & $60 \cdot 8$ & $13 \cdot 3$ & $26 \cdot 4$ & 1.66 & 2327 & 56035 & $60 \cdot 3$ & $13 \cdot 1$ & $26 \cdot 3$ & 1.59 & 1888 \\
\hline & +1 or more & 20105 & $62 \cdot 1$ & 13.4 & $26 \cdot 4$ & 1.65 & 1557 & 25482 & $61 \cdot 3$ & $13 \cdot 2$ & $26 \cdot 0$ & 1.60 & 1257 \\
\hline & $P$ value $\neq$ & & $<0.001$ & 0.08 & 0.02 & 0.17 & $<0.001$ & & $<0.001$ & $<0.001$ & $<0.001$ & $<0.001$ & $<0.001$ \\
\hline
\end{tabular}

MET, metabolic equivalents.

† MET of activity per day.

$\ddagger P_{\text {for trend }}$ according to the $t$ test. 


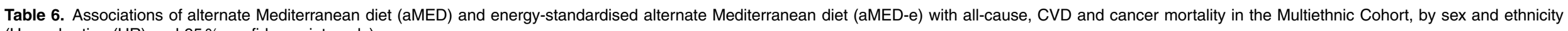
(Hazard ratios (HR) and 95\% confidence intervals)

\begin{tabular}{|c|c|c|c|c|c|c|c|c|c|c|c|c|c|c|c|c|c|c|c|c|c|c|c|c|c|}
\hline \multirow[b]{3}{*}{ Outcomes } & \multirow[b]{3}{*}{ Index } & \multicolumn{12}{|c|}{ Men } & \multicolumn{12}{|c|}{ Women } \\
\hline & & \multicolumn{2}{|c|}{$\begin{array}{l}\text { All races } \\
(n \text { 87 338) }\end{array}$} & \multicolumn{2}{|c|}{ White ( $n$ 21 992) } & \multicolumn{2}{|c|}{$\begin{array}{l}\text { African- } \\
\text { American } \\
(n \text { 12212) }\end{array}$} & \multicolumn{2}{|c|}{$\begin{array}{l}\text { Native Hawaiian } \\
\text { (n 6051) }\end{array}$} & \multicolumn{2}{|c|}{$\begin{array}{l}\text { Japanese } \\
\text { American } \\
(n 25945)\end{array}$} & \multicolumn{2}{|c|}{ Latino ( $n 21138)$} & \multicolumn{2}{|c|}{$\begin{array}{c}\text { All races } \\
(n 106189)\end{array}$} & \multicolumn{2}{|c|}{ White ( $n$ 25 546) } & \multicolumn{2}{|c|}{$\begin{array}{l}\text { African- } \\
\text { American } \\
(n \text { 21127) }\end{array}$} & \multicolumn{2}{|c|}{$\begin{array}{l}\text { Native Hawaiian } \\
\quad(n \text { 7838) }\end{array}$} & \multicolumn{2}{|c|}{$\begin{array}{l}\text { Japanese } \\
\text { American } \\
(n \text { 28 939) }\end{array}$} & \multicolumn{2}{|c|}{ Latino ( $n$ 22 739) } \\
\hline & & $\mathrm{HR} \dagger$ & $95 \% \mathrm{Cl}$ & $\mathrm{HR} \dagger$ & $95 \% \mathrm{Cl}$ & $\mathrm{HR} \dagger$ & $95 \% \mathrm{Cl}$ & $\mathrm{HR}+$ & $95 \% \mathrm{Cl}$ & $\mathrm{HR} \dagger$ & $95 \% \mathrm{Cl}$ & $\mathrm{HR} \dagger$ & $95 \% \mathrm{Cl}$ & $\mathrm{HR} \dagger$ & $95 \% \mathrm{Cl}$ & $\mathrm{HR} \dagger$ & $95 \% \mathrm{Cl}$ & $\mathrm{HR} \dagger$ & $95 \% \mathrm{Cl}$ & $\mathrm{HR} \dagger$ & $95 \% \mathrm{Cl}$ & $\mathrm{HR} \dagger$ & $95 \% \mathrm{Cl}$ & HR† & $95 \% \mathrm{Cl}$ \\
\hline \multirow[t]{3}{*}{ All causes } & aMED $\ddagger$ & $0.82^{*}$ & $0.79,0.85$ & $0.74^{\star}$ & $0.68,0.79$ & $0.84^{*}$ & $0.78,0.91$ & 0.96 & $0.84,1.09$ & $0.84^{*}$ & $0.78,0.9$ & $0.84^{\star}$ & $0.78,0.91$ & $0.85^{\star}$ & $0.82,0.89$ & $0.80^{*}$ & $0.74,0.87$ & $0.85^{\star}$ & $0.79,0.91$ & 0.97 & $0.85,1 \cdot 1$ & $0.83^{*}$ & $0.76,0.9$ & $0.89^{*}$ & $0.81,0.5$ \\
\hline & FDS & $0.77^{\star}$ & $0.74,0.80$ & $0.70^{\star}$ & & $0.78^{*}$ & $0.72,0.86$ & 0.88 & $0.76,1.02$ & $0.80^{*}$ & $0.74,0.86$ & $0.78^{\star}$ & & $0.79^{*}$ & & $0.75^{\star}$ & 0.82 & $0.73^{*}$ & & 0.91 & 0.7 & & & $0.88^{*}$ & \\
\hline & & $0.79^{*}$ & $0.76,0.82$ & $0.73^{\star}$ & $0.67,0.79$ & $0.80^{*}$ & $0.73,0.87$ & 0.90 & $0.78,1.04$ & $0.77^{\star}$ & & $0.83^{\star}$ & & $0.80^{*}$ & & $0.77^{*}$ & & 0.7 & & 0.95 & $0.82,1$ & & & 0.8 & \\
\hline \multirow[t]{3}{*}{ CVD } & aMED $\ddagger$ & $0.83^{*}$ & $0.78,0.88$ & $0.78^{\star}$ & $0.68,0.88$ & $0.81^{*}$ & $0.72,0.91$ & 0.9 & $0.73,1.11$ & $0.83^{*}$ & $0.74,0.94$ & $0.89^{\star}$ & $0.78,1.01$ & $0.84^{*}$ & $0.79,0.9$ & $0.76^{*}$ & $0.66,0.88$ & $0.88^{*}$ & $0.79,0.98$ & 1.04 & $0.83,1.31$ & $0.72^{*}$ & $0.62,0.83$ & 0.90 & $0.77,1.05$ \\
\hline & AFDS & $0.79^{*}$ & $0.74,0.85$ & $0.75^{\star}$ & $0.66,0.86$ & $0.77^{*}$ & $0.67,0.89$ & 0.82 & $0.65,1.03$ & $0.83^{*}$ & $0.73,0.94$ & $0.86^{\star}$ & & $0.78^{*}$ & $0.72,0.84$ & $0.73^{*}$ & $0.62,0.86$ & $0.76^{\star}$ & & 0.96 & $0.74,1$ & $0.69^{*}$ & 0.81 & 0.92 & $0.77,1 \cdot 10$ \\
\hline & aMED-e & $0.81^{*}$ & $0.76,0.86$ & $0.78^{\star}$ & $0.68,0.88$ & $0.78^{*}$ & $0.68,0.90$ & 0.83 & $0.66,1.03$ & $0.76^{*}$ & $0.67,0.87$ & 0.94 & $0.81,1.08$ & $0.77^{\star}$ & $0.72,0.83$ & $0.73^{*}$ & $0.62,0.85$ & $0.74^{\star}$ & $0.65,0.84$ & 0.99 & $0.77,1.28$ & $0.76^{*}$ & $0.64,0.90$ & 0.89 & $0.74,1.06$ \\
\hline \multirow[t]{3}{*}{ Cancer } & aMED $\ddagger$ & $0.84^{*}$ & $0.79,0.9$ & $0.75^{\star}$ & $0.66,0.86$ & $0.86^{*}$ & $0.75,0.98$ & 1.04 & $0.81,1.33$ & 0.92 & $0.82,1.05$ & $0.78^{\star}$ & $0.68,0.91$ & 0.92 & $0.86,0.99$ & 0.92 & & 0.92 & & 0.96 & & 1.04 & & $0.83^{*}$ & \\
\hline & aMED§ & $0.79^{\star}$ & $0.73,0.84$ & $0.71^{*}$ & $0.62,0.82$ & $0.81^{*}$ & $0.69,0.95$ & 0.94 & $0.71,1.23$ & $0.87^{*}$ & $0.76,0.99$ & $0.72^{\star}$ & $0.61,0.84$ & $0.87^{\star}$ & $0.80,0.94$ & 0.88 & $0.75,1.03$ & $0.81^{*}$ & $0.70,0.94$ & 0.96 & $0.73,1.26$ & 1.01 & $0.85,1 \cdot 20$ & $0.78^{*}$ & $0.64,0$ \\
\hline & aMED-e & $0.81^{*}$ & $0.76,0.87$ & $0.76^{*}$ & $0.66,0.87$ & 0.90 & $0.77,1.05$ & 0.96 & $0.75,1.24$ & $0.85^{\star}$ & $0.74,0.97$ & $0.68^{\star}$ & $0.57,0.80$ & $0.88^{*}$ & $0.81,0.94$ & 0.89 & $0.77,1.03$ & 0.84 & $0.73,0.97$ & 1.00 & $0.77,1.30$ & 0.99 & $0.83,1 \cdot 17$ & $0.79^{*}$ & $0.65,0.96$ \\
\hline
\end{tabular}

* Statistically significant $(P<0.05)$.

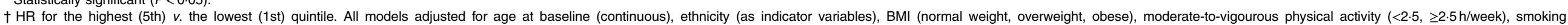

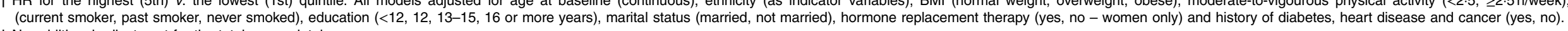

f No additional adjustment for the total energy intake.

$\S$ With additional adjustment for the total energy intake. 
components $^{(35)}$. In a recent commentary, Subar et al. (34) presented a thorough discussion on the limitations and merits of energy intakes derived from FFQ and advocated the use of energy intakes from self-reported dietary data for studies of dietary patterns, as a means of estimating contribution of specific foods to the overall diet. Adjustment for the total energy intake in models has been advocated for both standard and nutrient density approaches in nutrient intake assessment ${ }^{(20)}$.

In the estimation of an effect of Mediterranean diet on mortality risk, with additional adjustment for the total energy intake, risk estimates for the aMED score were very close to those for aMED-e among men and women across all ethnic groups. The estimates for aMED without energy adjustment in the model were not as close to those for adjusted aMED or aMED-e, although they were in the same direction. At the same time, estimates for aMED-e with and without additional energy adjustment were nearly identical (data not shown). This suggests that either aMED combined with total energy intake or aMED-e alone could be used to gauge a person's diet in terms of its effect on the risk of death. An investigator preferring a single quantity for this purpose may choose aMED-e, whereas someone striving for uniform methodology with prior research may opt for aMED. For the same reasons, comparison of results can be performed across studies using different versions of the score.

We note that Mediterranean diet indices, both traditional (MDS) and aMED, are based on scoring most food components relative to the population medians. Thus, they are population dependent, whereby different populations under study would entail varying score cut-off points. This approach has its advantages and drawbacks. One rationale for such a population-based scoring method is its flexibility: populations may differ in a variety of ways, such as prevailing attitudes towards eating and exercise, regional cuisine, availability of certain food items and not others, etc. Because of these and other factors, beneficial effects of consuming specific groups of foods may differ, and the composition of a diet score may need to be adjusted. Diet scoring based on population medians accomplishes such fine tuning of a dietary index. On the other hand, this approach complicates direct comparison across studies, because the same score in two populations may not represent the same level of intake or the same diet composition. In addition, median-based diet scores are not stable over time: if the general pattern in a population shifts towards increased consumption of healthy foods and therefore higher median intakes, individuals with no change in the diet may likely see their diet score drop. This is counterintuitive and may bias the results of studies temporally spaced apart.

These disadvantages could be overcome by using the same cut-off points (e.g. baseline medians) throughout repeat dietary assessments, as implemented by Hoevenaar-Blom et al. ${ }^{(36)}$, or by applying a scoring method with fixed cut-off points for component scores, similar to other diet scores such as Healthy Eating Index ${ }^{(37)}$ or Alternative Healthy Eating Index ${ }^{(38)}$. In the Prevención con Dieta Mediterránea (PREDIMED) study based in Spain, Estruch et al. ${ }^{(39)}$ used normative cut-off points and a fourteen-item MeDiet screener tool to quantify adherence to the Mediterranean diet. Sofi et $a l^{(5)}$ recently proposed a literature-based adherence score as a modification of the MDS dietary index. They reviewed a total of twenty-seven cohort studies from across three continents (Europe, North America and Australia) and defined the scoring cut-off points, separately for men and women, as means of the weighted medians from all individual studies. These are commendable efforts, even if the resulting cut-off points reflect only the included studies and may not be applicable in populations geographically and ethnically different from those surveyed. Fixed scoring cut-off points based on biological and epidemiological evidence would be better justified and more desirable.

Strengths of the present study include its large sample size, long follow-up and multi-ethnic composition, which makes our findings generalisable across multiple ethnic groups. The inclusion of ethnic-specific foods and calibration of the QFFQ within ethnic groups allowed us to better estimate intake levels by food group and the overall energy intake. Among the limitations of the present study, we note that only a baseline dietary assessment was available in our cohort. As a consequence, we were unable to examine diet change patterns and to investigate how diet change potentially affects mortality risk. In summary, although the individual aMED and aMED-e diet scores may substantially differ, both aMED versions, with energy standardisation built in and with energy adjustment at the analytic stage, show very similar reductions in all-cause, CVD and cancer mortality for individuals scoring high on the index scale. Therefore, either version of the score can be used in studies examining the association of diet with mortality. Moreover, results across such studies using different versions of the aMED score could be meaningfully compared in future meta-analyses.

\section{Acknowledgements}

The authors thank all the participants in the Multiethnic Cohort Study. We want to recognise Anne Tome of the University of Hawaii Cancer Center for her assistance in applying the indexes' criteria to the MEC food composition table. The authors thank Jill Reedy for helpful comments and guidance with the manuscript. The authors wish to acknowledge the Dietary Patterns Methods Project Working Group, including MEC: C. J. B., R. E., B. E. H.; Women's Health Initiative: Stephanie George, Marian Neuhouser; National Institutes of Health-AARP Diet and Health Study: Susan M. Krebs-Smith, Paige E. Miller, Jill Reedy, TusaRebecca Schap, Amy F. Subar; and University of South Carolina: Angela D. Liese.

Support for this work comes from the National Cancer Institute (HHSN261201200423P). The Multiethnic Cohort Study is supported by NIH/NCI 4R37 CA 54281. B. E. H. and R. E. were recipients of the post-doctoral fellowship R25 CA 90956. Partial support for this work also comes from the NIH/NCI P30 CA071789.

L. L. M., L. N. K. and C. J. B. were responsible for conception and design, acquisition of funding and overseeing the study; Y. B. S., L. R. W. and C. J. B. developed methodology; Y. B. S. analysed and interpreted the data; Y. B. S. and C. J. B. wrote the manuscript; B. E. H., R. E. and L. R. W. contributed to manuscript writing and editing.

The authors declare that there are no conflicts of interest. 


\section{Supplementary material}

For supplementary material/s referred to in this article, please visit http://dx.doi.org/10.1017/S0007114516003482

\section{References}

1. Trichopoulou A, Kouris-Blazos A, Wahlqvist ML, et al. (1995) Diet and overall survival in elderly people. BMJ 311, 1457-1460.

2. Trichopoulou A, Costacou T, Bamia C, et al. (2003) Adherence to a Mediterranean diet and survival in a Greek population. $N$ Engl J Med 348, 2599-2608.

3. Fung TT, McCullough ML, Newby PK, et al. (2005) Diet-quality scores and plasma concentrations of markers of inflammation and endothelial dysfunction. Am J Clin Nutr 82, 163-173.

4. Trichopoulou A, Martinez-Gonzalez MA, Tong TYN, et al. (2014) Definitions and potential health benefits of the Mediterranean diet: views from experts around the world. BMC Med 12, 112

5. Sofi F, Macchi C, Abbate R, et al. (2014) Mediterranean diet and health status: an updated meta-analysis and a proposal for a literature-based adherence score. Public Health Nutr 17, $2769-2782$.

6. Fung TT, Hu FB, McCullough ML, et al. (2006) Diet quality is associated with the risk of estrogen receptor-negative breast cancer in postmenopausal women. $J$ Nutr 136, 466-472.

7. Fung TT, Rexrode KM, Mantzoros CS, et al. (2009) Mediterranean diet and incidence of and mortality from coronary heart disease and stroke in women. Circulation 119, 1093-1100.

8. De Koning L, Chiuve SE, Fung TT, et al. (2011) Diet-quality scores and the risk of type 2 diabetes in men. Diabetes Care 34, 1150-1156.

9. Tobias DK, Hu FB, Chavarro J, et al. (2012) Healthful dietary patterns and type 2 diabetes mellitus risk among women with a history of gestational diabetes mellitus. Arch Inter Med 172, 1566-1572.

10. Li WQ, Park Y, Wu JW, et al. (2013) Index-based dietary patterns and risk of esophageal and gastric cancer in a large cohort study. Clin Gastroenterol Hepatol 11, 1130-1136 $\mathrm{e} 1132$.

11. Li WQ, Park Y, Wu JW, et al. (2014) Index-based dietary patterns and risk of head and neck cancer in a large prospective study. Am J Clin Nutr 99, 559-566.

12. Li WQ, Park Y, McGlynn KA, et al. (2014) Index-based dietary patterns and risk of incident hepatocellular carcinoma and mortality from chronic liver disease in a prospective study. Hepatology 60, 588-597.

13. Koloverou E, Esposito K, Giugliano D, et al. (2014) The effect of Mediterranean diet on the development of type 2 diabetes mellitus: a meta-analysis of 10 prospective studies and 136,846 participants. Metabolism 63, 903-911.

14. Lopez-Garcia E, Rodriguez-Artalejo F, Li TY, et al. (2014) The Mediterranean-style dietary pattern and mortality among men and women with cardiovascular disease. Am J Clin Nutr 99, $172-180$.

15. George SM, Ballard-Barbash R, Manson JE, et al. (2014) Comparing indices of diet quality with chronic disease mortality risk in postmenopausal women in the Women's Health Initiative Observational Study: evidence to inform national dietary guidance. Am J Epidemiol 180, 616-625.

16. Reedy J, Krebs-Smith SM, Miller PE, et al. (2014) Higher diet quality is associated with decreased risk of all-cause, cardiovascular disease, and cancer mortality among older adults. $J$ Nutr 144, 881-889.

17. Harmon BE, Boushey CJ, Shvetsov YB, et al. (2015) Associations of key diet-quality indexes with mortality in the multiethnic cohort: the Dietary Patterns Methods Project. Am J Clin Nutr 101, 587-597.

18. Liese AD, Krebs-Smith SM, Subar AF, et al. (2015) The Dietary Patterns Methods Project: synthesis of findings across cohorts and relevance to dietary guidance. J Nutr $\mathbf{1 4 5}$, 393-402.

19. Hoevenaar-Blom MP, Nooyens AC, Kromhout D, et al. (2012) Mediterranean style diet and 12-year incidence of cardiovascular diseases: the EPIC-NL cohort study. PLOS ONE 7, e45458.

20. Willett WC, Howe GR \& Kushi LH (1997) Adjustment for total energy intake in epidemiologic studies. Am J Clin Nutr $\mathbf{6 5}$, 1220-1228.

21. Kolonel LN, Henderson BE, Hankin JH, et al. (2000) A multiethnic cohort in Hawaii and Los Angeles: baseline characteristics. Am J Epidemiol 151, 346-357.

22. Centers for Disease Control and Prevention (2009) International Classification of Diseases, 9th revision. $\mathrm{ftp}: / / \mathrm{ftp} . \mathrm{cdc}$. gov/pub/Health_Statistics/NCHS/Publications/ICD9-CM/2009/ (accessed February 2014).

23. World Health Organization (2013) International Statistical Classification of Diseases and Related Health Problems, 10th revision. http://apps.who.int/classifications/icd10/browse/ 2010/en (accessed February 2014).

24. Stram DO, Hankin JH, Wilkens LR, et al. (2000) Calibration of the dietary questionnaire for a multiethnic cohort in Hawaii and Los Angeles. Am J Epidemiol 151, 358-370.

25. Sharma S, Murphy SP, Wilkens LR, et al. (2003) Extending a multiethnic food composition table to include standardized food group servings. J Food Compos Anal 16, 485-495.

26. Murphy SP (2002) Unique nutrition support for research at the Cancer Research Center of Hawaii. Hawaii Med J 61, 15-17.

27. Bowman SA, Friday JE \& Moshfegh A (2008) MyPyramid Equivalents Database, 2.0 for USDA Survey Foods, 2003-2004. http://www.ars.usda.gov/SP2UserFiles/Place/12355000/pdf/ mped/mped2_doc.pdf (accessed February 2014).

28. Grambsch PM \& Therneau TM (1994) Proportional hazards tests and diagnostics based on weighted residuals. Biometrika 81, 515-526.

29. Westerterp KR (2010) Physical activity, food intake, and body weight regulation: insights from doubly labeled water studies. Nutr Rev 68, 148-154.

30. Blundell JE \& King NA (1999) Physical activity and regulation of food intake: current evidence. Med Sci Sports Exerc 31, S573-S583.

31. Freedman LS, Commins JM, Moler JE, et al. (2014) Pooled results from 5 validation studies of dietary self-report instruments using recovery biomarkers for energy and protein intake. Am J Epidemiol 180, 172-188.

32. Subar AF, Kipnis V, Troiano RP, et al. (2003) Using intake biomarkers to evaluate the extent of dietary misreporting in a large sample of adults: the OPEN study. Am J Epidemiol 158, 1-13.

33. Willett W (2013) Nutritional Epidemiology, 3rd ed. Oxford: Oxford University Press.

34. Subar AF, Freedman LS, Tooze JA, et al. (2015) Addressing current criticism regarding the value of self-report dietary data. J Nutr 145, 2639-2645.

35. Kipnis V, Subar AF, Midthune D, et al. (2003) Structure of dietary measurement error: results of the OPEN biomarker study. Am J Epidemiol 158, 14-21; discussion 22-16.

36. Hoevenaar-Blom MP, Spijkerman AM, Boshuizen HC, et al. (2014) Effect of using repeated measurements of a 
Mediterranean style diet on the strength of the association with cardiovascular disease during 12 years: the Doetinchem Cohort Study. Eur J Nutr 53, 1209-1215.

37. Guenther PM, Reedy J \& Krebs-Smith SM (2008) Development of the Healthy Eating Index-2005. J Am Diet Assoc 108, 1896-1901.
38. Guenther PM, Casavale KO, Reedy J, et al. (2013) Update of the Healthy Eating Index: HEI-2010. J Acad Nutr Diet 113, 569-580.

39. Estruch R, Martinez-Gonzalez MA, Corella D, et al. (2006) Effects of a Mediterranean-style diet on cardiovascular risk factors: a randomized trial. Ann Intern Med 145, 1-11. 